\title{
Entre o sucesso e o fracasso: desenvolvimento, sementes crioulas e transgênicas
}

\section{Between success and failure: development, native and transgenic seeds}

Vinícius Cosmos Benvegnú - Doutorando em Antropologia Social, no Programa de Pós-Graduação em Antropologia Social da Universidade Federal do Amazonas (PPGAS/UFAM). E-mail: vcbenvegnu@yahoo.com.br

Guilherme Radomsky - Doutor em Antropologia Social, pela Universidade Federal do Rio Grande do Sul (UFRGS). Professor do Departamento de Sociologia e dos Programas de Pós-Graduação em Sociologia (PPGS/UFRGS) e em Desenvolvimento Rural (PGDR/UFRGS) da Universidade Federal do Rio Grande do Sul (UFRGS). E-mail: guilherme.radomsky@ufrgs.br

\section{Resumo}

Neste artigo, analisamos práticas de agricultores familiares que cultivam sementes crioulas de milho num contexto de expressiva inserção de transgênicos no Brasil meridional. Examinamos quais discursos são acionados para que tais variedades tenham significativa expansão na região e as avaliações críticas realizadas pelos agricultores. Podemos considerar o incentivo ao plantio e à produção de variedades transgênicas enquanto uma iniciativa pertencente às dinâmicas de desenvolvimento? A pesquisa de caráter qualitativo foi realizada em Canguçu, Rio Grande do Sul, e mostrou que a adoção dos transgênicos tem efeitos diversos que, independente de representar sucesso ou fracasso do desenvolvimento, geram desejos, subjetividades e relações que (re)produzem desigualdades. Nesses contextos, eventos agropecuários são articulados para promover a ideia de que transgênicos trazem facilidade e produtividade. Mesmo com impactos na agrobiodiversidade e as percepções que os agricultores têm acerca de dificuldades e eventuais frustrações nas colheitas, é justamente isto que cria condições para novas iniciativas de "desenvolvimento".

\section{Palavra-chave}

Desenvolvimento. Sementes Crioulas. Transgênicos. Canguçu.

\begin{abstract}
In this article, we analyze practices of family farmers who cultivate native corn seeds (open source seeds) in a context of significant growth of transgenics in southern Brazil. We examine which speeches are triggered so that such varieties have significant expansion in the region and also the critical assessments by farmers. Can we consider encouraging the planting and production of transgenic varieties as an initiative belonging to the dynamics of development? The qualitative research was carried out in Canguçu, Rio Grande do Sul, Brazil, and showed that the adoption of transgenics has several effects. Regardless it represents success or failure of development, this initiative generates desires, subjectivities and relationships that (re) produce inequalities. In these contexts, rural events and seminars are articulated to promote the idea that transgenics bring easiness and productivity. Even with impacts on agrobiodiversity and perceptions that farmers have about difficulties and possible frustrations in the harvests, this is exactly what creates conditions for new "development" initiatives.
\end{abstract}

\section{Keywords}

Development. Native Seeds. Open Source Seeds. Transgenics. Canguçu. 


\section{INTRODUÇÃO}

Neste artigo, apresentamos parte dos resultados de pesquisa realizada com agricultores familiares, também pequenos proprietários rurais, que cultivam sementes crioulas de milho no município de Canguçu, localizado no sul do estado do Rio Grande do Sul. Este município é conhecido como, e também se autointitula, a "capital latino-americana do minifúndio". A trama rural é composta por quase quatorze mil pequenas propriedades, caracterizadas como propriedades da agricultura familiar. Essa alcunha se dá devido à presença de mais de quinze assentamentos da reforma agrária, ademais de sua diversidade étnica, como a presença de etnias indígenas, afrodescendentes - são mais de dezesseis quilombos - e de descendentes europeus, lusos, hispânicos, ítalos e germânicos. Levando em conta que diversidade gera diversidade, é possível constatar que nessas pequenas propriedades ainda há uma diversidade tanto de agriculturas como espécies e variedades vegetais cultivadas.

Neste contexto, o cultivo de variedades crioulas não se configura apenas em uma atividade econômica, mas também, como será demonstrado ao longo do texto, em uma luta política em defesa da conservação da agrobiodiversidade. Dessa forma, no cotidiano em que estes agricultores estão inseridos realizam um importante enfrentamento face ao crescente cultivo e comércio de organismos geneticamente modificados de milho, popularmente conhecidos como transgênicos. O questionamento que permeia este trabalho é: podemos considerar o incentivo ao plantio e à produção, e o consumo de variedades transgênicas, um empreendimento pertencente às dinâmicas de desenvolvimento?

Dessa forma, o escopo do artigo é uma reflexão acerca de quais elementos e discursos são acionados para que as variedades transgênicas tenham essa crescente expansão e algumas consequências que, independente do seu sucesso ou fracasso, geram desejos, subjetividades e relações que (re)produzem desigualdades sociais. As avaliações críticas e contestações a respeito do sucesso dos transgênicos também serão analisadas, com especial atenção aos modos de entendimento que elaboram agricultores e agricultoras.

A pesquisa que originou o conjunto de dados aqui examinados foi realizada por um dos autores do artigo no primeiro semestre de 2016, especialmente entre os meses de fevereiro e julho. Priorizando as técnicas qualitativas de investigação, foram realizadas entrevistas e observações dando contornos a um trabalho de inspiração etnográfica que levou a sério o que Roberto Cardoso de Oliveira (2006) salientou enquanto central para a prática do antropólogo: olhar, ouvir, escrever. 
Para o debate analítico da antropologia do desenvolvimento, lançamos mão dos estudos de David Mosse (2005) e James Ferguson (1990). Estes autores apresentam trabalhos etnográficos substanciais que embasam importantes discussões e críticas ao desenvolvimento enquanto modelo político, econômico e social. As etnografias feitas por esses autores possuem procedimentos metodológicos distintos e que não foram referenciais na pesquisa aqui apresentada. Também nos valemos dos estudos de Arturo Escobar (2007) acerca do pósdesenvolvimento e as críticas ao desenvolvimento. Assim, as orientações teóricometodológicas de tais autores serão menos enfatizadas do que a densidade de tais estudos e o quanto aportam para o debate a respeito do sucesso ou o fracasso das iniciativas de desenvolvimento.

No que segue, são apresentadas narrativas a respeito de sementes híbridas e dos artefatos transgênicos e, logo após, a questão que denominamos de sementes do desenvolvimento. $\mathrm{Na}$ seção seguinte, problematizam-se o sucesso dos transgênicos e, ao final, o fracasso e o sucesso das biotecnologias geneticamente modificadas, isto é, como alteram também outras ordens da realidade, colocando em xeque justamente o desenvolvimento. Na última seção, tecemos algumas considerações finais gerais acerca das reflexões propostas aqui.

\section{PRODUTIVIDADE E FACILIDADE, NARRATIVAS HÍBRIDAS E TRANSGÊNICAS}

Nos caminhos tortuosos da Serra dos Tapes, entre subir um morro e descer outro, as encostas ainda mantinham o orvalho da noite anterior. Contudo, o frescor da manhã que recém nascia não nos enganava, o dia prometia ser quente, afinal era verão! Próximo das oito horas da manhã já estávamos adentrando a propriedade do sr. Cléu Ferreira. Ele por sua vez já sabendo de nossa chegada, esperava-nos na varanda da casa com o mate cevado, pronto para a conversa. Ao apearmos do carro fomos apresentados, sr. Cléu e eu, por intermédio do sr. Júlio, amigo e meu "cicerone" em Canguçu. Após algumas térmicas de mate, e uma conversa prazerosa, o sr. Cléu fez questão de mostrar os arredores de sua casa. As criações de galiformes e o pomar adjacente ao pátio, de onde colhe as frutas para o fabrico de suco integral na sua agroindústria familiar localizada atrás da casa. Encerramos nossa visita despedindo-nos e com a promessa de seguir a conversa. Nessa ocasião foi que um dos autores deste artigo conheceu o sr. Cléu Ferreira.

O sr. Cléu Ferreira, além de ser agricultor familiar que vive no município de Canguçu, na porção sul do Rio Grande do Sul, é um dos fundadores da União das Associações Comunitárias do Interior de Canguçu (doravante, Unaic), 
do banco de sementes e do grupo produtor de sementes crioulas da mesma associação. A Unaic é uma importante organização local que surgiu há quase trinta anos a fim de desenvolver atividades relacionadas à produção e comércio de produtos da agricultura familiar daquele município. Entretanto, a Unaic se destaca regionalmente pelo trabalho com as sementes crioulas, "atualmente a Unaic trabalha exclusivamente assessorando, recebendo, beneficiando e comercializando as sementes crioulas dos agricultores produtores. Além disso, a associação mantém o trabalho de resgate, resguardo e divulgação das sementes" (UNAIC, 2016, s/p). Além das atividades agrícolas, o sr. Cléu Ferreira está envolvido com atividades militantes acerca dos temas pertinentes ao mundo rural. Ao longo da pesquisa, foi possível conversar com ele em algumas ocasiões, contudo foi nessa primeira vez que estive em sua propriedade que me relatou um "causo" que seu pai viveu com o milho híbrido.

Esta variedade recém havia chegado ao município, era a década de 1960, e ainda estava envolta entre o desconhecido e a inovação. Seu pai iria cultivar a variedade pela primeira vez. Como esperado (pela indústria da semente e pelo agricultor) ao plantá-la, a semente melhorada gerou um milharal vistoso, verde, pujante, chegando a ter duas ou mais espigas em cada cana. Os vizinhos ao verem o milharal admiravam-se e elogiavam o cultivo. Como de praxe, pediram ao senhor que lhes reservasse algumas sementes para que pudessem também plantar no ano seguinte. Chegada a época de plantio da nova safra, o pai do sr. Cléu Ferreira distribuiu as sementes entre os vizinhos, porém alertou-lhes que havia escutado que as sementes daquele milho guardadas de um ano para o outro não produziam da mesma forma que a comprada a cada ano. Os agricultores, entretanto, não lhe deram muito crédito. O pensamento geral era de que se havia produzido bem em um ano deveria ser o mesmo no seguinte, seguindo assim a lógica do milho crioulo que sempre haviam plantado.

Feito o plantio das sementes híbridas, o milharal foi crescendo e desde o princípio já dava indícios de que não seria igual à plantação anterior, como aquela do pai do sr. Cléu Ferreira. Na época da colheita as previsões se confirmaram. Além de produzir menos, aquelas espigas eram notadamente menores e menos desenvolvidas que as primeiras. Não convencidos, e responsabilizando outros fatores, houve vizinhos que tentaram plantar uma terceira safra. O resultado mostrou-se pior ainda. Por fora as espigas pareciam vistosas e com boa "palhada". No entanto, ao abrirem as espigas praticamente não havia grãos! Esta sucessão de acontecimentos acabou convertendo-se em burlas e piadas para com pai do sr. Cléu Ferreira, em que a vizinhança apontava que o "seu" novo milho era falhado. 
O episódio ocorrido com o pai do sr. Cléu Ferreira aconteceu na década de 1960, contudo a chegada massiva da Revolução Verde e todas suas dinâmicas e discursos, em Canguçu, deu-se apenas na década de 1980, conforme corroboravam diversos agricultores. José Luís (Zé Luís) é outro conhecido agricultor do município, também associado à Unaic, foi ele quem nos falou a respeito das relações entre introdução de variedades híbridas e transgênicas, em Canguçu. Durante uma conversa ao pé do fogão a lenha, enquanto conversávamos sobre as expectativas da colheita que se avizinhava, ele recordou esses episódios. O milho híbrido chegara nos anos 1980, via extensão rural, "eles levavam o pacote da Revolução Verde de uma sementeira. Eles passavam aquilo ali. Eles te davam a sementes, o adubo, a ureia ${ }^{1}$, só que tu levava [no sentido de divulgar] o nome deles. E assim difundiam o pacote" (PORTO, 2016)².

Desse relato, o sr. Zé Luís Porto teceu alguns comentários acerca das dinâmicas agrícolas ocorridas em Canguçu. Após um momento de silêncio reflexivo de todos, indaguei-lhe como e quando os transgênicos haviam sido inseridos no município. Após fazer alguns cálculos mentais ele afirmou que não fazia nem dez anos que esse tipo de "tecnologia" chegara ali. Essa pergunta, no entanto, desencadeou reflexões profundas sobre os transgênicos.

Hoje eles passam [no sentido de informar, vender o produto] que é a facilidade, que o agricultor vai lá e produz. Que pode botar o glifosato por cima do milho. Porque quem criou essa ideia do transgênico, quem vende as sementes, é quem vende o glifosato. Então hoje o pacote é, 'te vendo o milho e vendo o glifosato', porque é mais fácil de fazer. E é mais fácil para quem planta bastante. Mas os caras estão introduzindo na cabeça dos pequenos que também é mais fácil para ele.

[pausa retórica]

Teve muita gente que entendeu que o transgênico era uma semente que ia produzir além do híbrido ainda. E isso passou muito na cabeça das pessoas, que o transgênico ia ser uma semente mais melhorada. E muita gente plantou ele pensando que iria ter uma produtividade ainda maior, só que a produtividade dele não foi. A ideia do transgênico não foi de ter uma produtividade maior, foi de facilitar, para o agricultor botar o veneno, não precisar capinar e ele plantar uma área maior. Não foi bem para o pequeno, só que o pequeno pensou em fazer uma produtividade maior e ele não conseguiu. $O$ transgênico nem é para produzir a qualidade. Ele é para produzir a facilidade, para vender o pacote ele tem que produzir a facilidade (PORTO, 2016).

Os relatos dos senhores Cléu Ferreira e Zé Luís Porto nos mostram como, primeiramente, as agências de extensão rural estavam intimamente relacionadas

Fertilizante químico rico em nitrogênio usado para adubação em larga escala.

Todas as entrevistas estão referenciadas ao final do artigo. 
com as empresas do agronegócio. Mas, a principal informação é evidenciar as expectativas que essas variedades melhoradas em laboratórios geram nos agricultores, além das estratégias utilizadas, na prática, para demonstrar e convencer as pessoas das vantagens previstas.

Situações como estas ou semelhantes - incentivos feitos por agentes externos e adoção por agricultores, consequentes frustrações e problemas, geralmente culpando os próprios produtores - podem ser recorrentes na agricultura e, muitas vezes, parecem depender de muitas variáveis explicativas para se responder sobre as causas deste fracasso. Interessa-nos, neste texto, analisar como o incentivo ao plantio de sementes híbridas, mas principalmente transgênicas, em Canguçu, está relacionada com processos de desenvolvimento e como os agricultores de Canguçu se posicionam quanto a estas situações, gerando práticas diversas. Ademais disso, cabe registrar que todos esses eventos convergem em uma reação emblemática: o resgate, manutenção e plantio de sementes crioulas também conhecidas como variedades locais desenvolvidas e manejadas pelos próprios agricultores.

\section{AS SEMENTES DO DESENVOLVIMENTO}

Inicialmente é necessário ter em conta que o desenvolvimento é resultado da razão moderna ocidental (RIST, 2002) e, dessa forma, valeu-se de mecanismos dessa ordem, tais como: construção de regimes de verdade e conhecimento, homogeneização e simplificação de vida, burocracia, ciência e tecnologia ${ }^{3}$. Rist (2002), Esteva (1996) e Sachs (2005) apontam que o desenvolvimento enquanto um projeto político, econômico e social emerge no devastado cenário europeu no pós-guerra de 1945. A partir de então essa ideia-força ganhará uma proeminência tal no cotidiano das sociedades eurorreferenciadas a ponto de ser compreendida comparavelmente a uma crença religiosa (RIST, 2002). Sendo assim, distintos estudos críticos do desenvolvimento buscam refletir como este "princípio" tornou-se tão potente e arraigado não somente no cotidiano vivido, mas também no imaginário das pessoas (PERROT, 2008; ESTEVA, 1996; RIBEIRO, 2008).

Desde então, a temática do desenvolvimento vem sendo escopo de trabalhos das ciências sociais e da antropologia do desenvolvimento. Segundo Rist (2002), a primeira dificuldade dentro das ciências sociais foi/é a de dar uma definição ou conceitualizar a palavra desenvolvimento que, em certos momentos,

A literatura que compreende o tema é extensa e algumas das análises que auxiliam a situar o fenômeno examinado no artigo são referidas ao longo deste texto. Para outras referências relevantes e recentes, remetemos o leitor aos estudos de Li (2007), DeVries (2007), Cesarino (2012), Kapoor (2008), Carneiro (2012), Goldman (2005). 
designa um estado e, em outros, um processo, relacionando-se a ideias de bemestar, progresso, justiça social, crescimento econômico, expansão individual e equilíbrio ecológico. Há ainda definições implícitas às ideias de evolucionismo social, individualismo e economicismo. Contudo, os trabalhos mais recentes nessas áreas procuram apontar como o desenvolvimento continua se "reproduzindo" e produzindo desejos e subjetividades, em que pese seus constantes fracassos (QUINTERO, 2015; SHEPHERD, 2004).

Um dos críticos proeminentes ao desenvolvimento é o colombiano Arturo Escobar. Sua vasta obra, muito influenciada pelos estudos de Edward Said, Valentin Y. Mudimbe, Chandra Mohanthy e de Michel Foucault entre outros, preocupase em trazer à tona esses mecanismos da modernidade e como eles operam na construção dos discursos de desenvolvimento. Para o autor, o desenvolvimento é, antes de tudo, um conjunto de práticas, conceitos e teorias que produzem categorias, subjetividades, desejos, relações de poder. Numa passagem, afirma:

Para entender o desenvolvimento como discurso é necessário entender não os elementos em si, mas ao sistema de suas relações recíprocas. É este sistema de relações que permite a criação sistemática de objetos, conceitos e estratégias; ele determina o que se pode pensar e dizer. Tais relações estabelecidas entre instituições, processos socioeconômicos, formas de conhecimento, fatores tecnológicos, etc. - definem as condições sob as quais podem se incorporar ao discurso, objetos, conceitos, teorias e estratégias. Isto é, o sistema de relações estabelece uma prática discursiva que determina as regras do jogo: quem pode falar, desde que pontos de vista, com que autoridade e segundo quais qualificações (ESCOBAR, 2007, p. 80).

Assim, é possível afirmar que antes mesmo que saia do papel dos projetos e dos escritórios das agências, o desenvolvimento conta com a crença prévia das próprias pessoas de que suas vidas poderão melhorar. Sendo seu principal mecanismo que viabiliza esta crença as construções narrativas que o elaboram como um "princípio organizador da vida social" (ESCOBAR, 2005, p. 20) 4 Projetos de desenvolvimento são elaborados com a "boa intenção" de que ao serem executados proporcionarão melhorias nas condições de vida de seus beneficiários.

No incentivo à adoção de novas tecnologias no campo, ou seja, a modernização e o incremento (bio)tecnológico, expectativas de aumento de produtividade e projeção para o futuro como o progresso, encontramos a convergência com o tema do desenvolvimento. Deste modo, da mesma forma que o desenvolvimento, podemos analisar que as variedades transgênicas também se estabelecem e se legitimam por meio de recursos discursivos. As narrativas

${ }^{4}$ Todas as citações cujos originais não estão em língua portuguesa foram traduzidas pelos autores. 
sobre estas variedades são construídas a fim de que se vendam possibilidades transformadoras às famílias de agricultores. Todavia, a evidenciação e a descoberta das debilidades, fragilidades e consequências indesejadas ficam por conta dos próprios agricultores.

Como aponta o relato do sr. Cléu Ferreira, quando as variedades híbridas recém entravam no cenário agrícola, nos idos anos 1960, as narrativas davam conta da produtividade, da eficácia que elas traziam consigo e, no limite, uma loa a um futuro de prosperidade. O milharal do pai do sr. Cléu Ferreira criou um imaginário e uma perspectiva de que aquela variedade chegava com um potencial transformador para os agricultores, em que pese os alertas do próprio senhor e as constatações geradas nas safras seguintes.

Bastaram duas ou três safras para que os agricultores percebessem que a eficácia era efêmera e que a promessa não era tão transformadora. Viram que para terem cultivos vistosos e produtivos daquelas sementes teriam de comprá-las e não apenas guardá-las de um ano para o outro, como faziam com as sementes até então usadas. Esta mercantilização veio a aparecer como um efeito indesejado e imprevisto, cuja problemática se acasala bem ao que Rist (2002, p. 13) define como desenvolvimento: um conjunto de práticas que para efetivar a reprodução da sociedade visa à destruição do ambiente natural e das relações sociais e cujo objetivo é aumentar a produção de mercadorias (bens e serviços).

No diálogo com o sr. Zé Luís Porto podem-se evidenciar dois dos principais argumentos utilizados pelos promotores do agronegócio para vender as sementes transgênicas: produtividade e facilidade. Se nos dedicássemos a realizar uma análise dos discursos pró-variedades transgênicas, o principal argumento ficaria por conta do eixo plantio/produtividade. O aumento da produtividade opera como um "encantador de serpentes" da melódica narrativa dessas sementes. Em outro momento daquela conversa, o sr. Zé Luís Porto havia nos explicado que o incremento de produtividade para as variedades híbridas, na década de 1980, não estava no emprego da tecnologia, mas em um artifício de cálculo. No dia de campo - momento de promover as sementes híbridas os técnicos de extensão rural se valiam da seguinte artimanha, de toda a área plantada "ao invés de pegar dez carreiros [que equivaleria proporcionalmente a 100\% da área], pegavam onze carreiros, claro aí tu aumentavas em 10\% a produtividade [ou seja, 110\%]" (PORTO, 2016).

Já para as variedades transgênicas são empregados os valores da tecnologia e diminuição do trabalho a ser realizado, culminando na promessa da facilidade. A ideia de facilidade é recorrente durante a fala do sr. Zé Luís Porto em três momentos e reforça este aspecto, "A ideia do transgênico não 
foi de ter uma produtividade maior, foi de facilitar, hoje eles passam [a ideia de] que é a facilidade; Mas ele [o transgênico] nem é para produzir a qualidade. Ele é para produzir a facilidade, para vender o pacote ele tem que produzir a facilidade" (PORTO, 2016, grifos nossos).

Assim, temos o discurso da "facilidade" operando legitimado pelo argumento da tecnologia ${ }^{5}$. Variedades que são "melhoradas" em laboratórios elevadas tecnologias de arranjos genéticos - ganham a legitimidade científica para serem vendidas como mais produtivas, mais rentáveis e menos demandante de mão-de-obra ${ }^{6}$. Em um evento durante a semana do meio ambiente em Canguçu, no ano de 2016, um dos palestrantes falava sobre os perigos do uso de agrotóxicos e, consequentemente, falou sobre os transgênicos. Ao falar sobre essas variedades disse que "o transgênico é mais produtivo porque é transgênico, e não é transgênico porque é mais produtivo" (informação verbal) ${ }^{7}$. Ele estava querendo mostrar que se crê no aumento de produtividade porque a variedade em questão carrega consigo a manipulação e saber técnico-científico, a transgenia.

Ainda que possam existir variedades transgênicas altamente produtivas, o sr. Zé Luís Porto amplia os obstáculos que os transgênicos trazem para os pequenos agricultores ao refletir acerca do cálculo econômico, ou seja, o cálculo entre gastos de produção e retorno esperado.

Esses dias estava olhando os preços das sementes de milho. O valor de seiscentos reais o pacote de 60.000 sementes, vinte quilos aproximado [referência: julho/2016]. Aí eu fiquei pensado, quanto o cara tem que produzir a mais para superar um varietal desses nossos aqui, ou um crioulo, que têm capacidade de cinquenta, sessenta, setenta sacos, dependendo até mais do que isso, pode chegar até aos cem sacos por hectare? Então, dependendo do valor, tem que produzir vinte ou trinta sacos a mais só para pagar a semente (PORTO, 2016).

Assim, o cálculo entre o valor de um pacote de sementes transgênicas e o quanto a mais um agricultor necessita produzir apenas para quitar aquele

5 Estudos clássicos sobre campesinato e modernização da agricultura haviam interpretado o comportamento camponês ora orientado para evitar o risco de perdas de safras, ora orientado para diminuição da penosidade no trabalho agrícola. Esta discussão parece ser retomada para o evento da transgenia. Duas belas revisões da literatura clássica são feitas por Woortmann (1995) e Abramovay (1998).

6 Melgarejo (2013), ao discorrer sobre a transgenia no Brasil, elenca os principais argumentos presentes nos discursos pró-transgênicos, "o futuro [com os transgênicos] estava na facilidade de controle de pragas e inços, nos grãos mais produtivos, nas plantas com características superiores em termos da qualidade de alimentos, nas plantas protetoras do ambiente e da saúde, que exigiriam menores aplicações de agrotóxicos menos perigosos, nas plantas tolerantes à seca e à salinidade" (MELGAREJO, 2013, p. 68, grifos nossos).

7 Informação fornecida por Leonardo Melgarejo, em Canguçu, durante palestra na Semana do Meio Ambiente, em junho de 2016. 
valor não depende somente da tecnologia presente na semente, mas de todo o pacote tecnológico envolvido. Fator que eleva os custos de produção, muitas vezes inviabilizando-a a pequenos agricultores.

Uma vez mais temos evidências de que variedades de sementes transgênicas fazem parte do conjunto de empreendimentos do desenvolvimento, pois nos discursos do desenvolvimento a tecnologia é pensada como um elemento que possibilita o progresso material, bem como aponta a direção e o significado do mesmo. Porém, não somente isto, já que, como sugere Escobar (2007, p. 73), a tecnologia foi concebida como uma "espécie de força moral que operaria criando uma ética da inovação, da produção e do resultado", contribuindo assim para expandir os ideais e a razão moderna. Não é à toa que a adesão aos transgênicos foi e é intensa, algo que remete a um sentimento de "não ficar para trás".

Ao analisar um programa de desenvolvimento rural implantado nas décadas de setenta e oitenta do século XX na Colômbia ${ }^{8}$, Escobar (2007) mostra que, sem desconsiderar os resultados econômico-estatísticos referentes à produção e incremento de renda, aquele projeto criou novos mecanismos de controle social. Segundo ele, o projeto não se restringia apenas ao "público alvo", estava interessado na "formação de semiproletários e proletários, com a articulação da produção camponesa com a agricultura comercial, e com a do setor agrário em geral e o resto da economia, especialmente o setor gerador de divisas" (ESCOBAR, 2007, p. 248).

Dessa forma, todos estes elementos discursivos do desenvolvimento produtividade, facilidade, ciência e tecnologia, progresso e prosperidade - são mecanismos que operam a fim de produzir classificações e relações de poder que possibilitaram dividir e hierarquizar as populações simplificando realidades. Produzem, ainda, desejos de transformações positivas dos cotidianos. E, no limite, produzem normatização de corpos e subjetividades. As sementes transgênicas, por sua vez, simplificam realidades agrícolas, modelos de agricultura, diversidade de culturas ${ }^{9}$. Por fim, da mesma forma, produzem desejos. Qual agricultor não

8 O programa em questão se chamava Desenvolvimento Rural Integrado (DRI), teve início em 1976 e foi financiado pelo Banco Mundial. Seu "público alvo" eram as "pequenas unidades de produção, conhecido convencionalmente como o subsetor tradicional ou atrasado, e mais recentemente como 'economia camponesa'. [Seu principal objetivo era] incrementar a produção de alimentos dentro da população escolhida, racionalizando a inserção do setor na economia de mercado" (ESCOBAR, 2007, p. 236-237).

9 Alguns estudos sustentam que a diminuição das variedades agrícolas pode se associar ao afunilamento de saberes na agricultura. De algum modo, os pacotes tecnológicos envolvendo sementes e variedades funcionam tal como a própria gramática do desenvolvimento, uma única receita para mudança social e técnica pode servir para uma diversidade de países e regiões (LI, 2000; BRUSH, 2005; NAZAREA, 2006; ver também ESCOBAR, 1999; INGOLD, 2005). 
deseja incrementar sua renda, ter mais forragem por meio da produtividade em grãos e consequentemente melhorar as condições de vida de sua família? Além de a produtividade ser relativa (deve ser colocada à prova e isto envolve custos adicionais e imprevisibilidades, tais como as ambientais e sociais), e de que as promessas são diferentes da realidade da produção agrícola, nem sempre, porém, como aponta o sr. Zé Luís Porto, a facilidade significa melhoria:

Um senhor de idade com um pulverizador nas costas, e eu com qualquer cavalo velho, faço duas vezes o serviço que ele vai fazer com o pulverizador e não corro risco de me contaminar e de contaminar a terra também, e porque a terra, se eu contaminar, vai ser por gerações e gerações (PORTO, 2016).

\section{EM QUE SENTIDO SE PODE FALAR EM SUCESSO NA TRANSGENIA E NO DESENVOLVIMENTO?}

Ainda que as narrativas transgênicas e de desenvolvimento sejam os primeiros artifícios a entrarem em contato com os agricultores, elas existem porque se tornam, de fato, realidades "plantadas na terra". Assim, algumas questões que emergem são: como os transgênicos se sustentam no cotidiano? E, ademais, como sementes manipuladas em laboratórios e arranjadas dentro de um projeto de desenvolvimento levam a transformações, muitas vezes profundas, nos cotidianos e nas vidas das pessoas, e, como consequência, logram ter êxito? Para pensar sobre as sementes transgênicas, orientamos a análise a seguir por um instigante estudo que se debruçou justamente em entender como projetos de desenvolvimento acabam sendo considerados exitosos, desde sua concepção até sua execução final em determinada comunidade.

David Mosse (2005), em sua etnografia sobre projetos de desenvolvimento rural na Índia, aponta algumas reflexões sobre o êxito ou o sucesso ${ }^{10}$ destes projetos. O autor está interessado em analisar como um projeto de desenvolvimento é realizado, administrado e torna-se bem sucedido. Uma das premissas do estudo de seu estudo é saber como um projeto de desenvolvimento é "sustentado e construído socialmente" (MOSSE, 2005, p. 158). Ou seja, importa como e para quem os projetos se dirigem e o que é feito para que ele tenha crédito. Nesse sentido, aponta o autor, os projetos de desenvolvimento estão num constante trânsito das ideias para realidade e da realidade para as ideias.

10 Trazemos aqui o conceito de sucesso, pois este é usado por Mosse, especialmente no capítulo "The social production of development success" do livro "Cultivating development" (MOSSE, 2005). 
Para realizar sua etnografia, Mosse (2005) lançou mão do estudo de redes como ferramenta metodológica. Seu trabalho foi o de seguir as redes - do projeto e das ideias do projeto - e as conexões entre elas que sustentavam seu sucesso ou fracasso. Segundo o autor, o sucesso de um projeto depende da execução eficiente de seus programas e a adesão de quem os executa - observadores externos, políticos, financiadores e a participação das pessoas locais aonde as ações são realizadas. A falha ou insucesso dos projetos de desenvolvimento não é "fracasso em transformar os projetos em realidade, mas a consequência de certa desarticulação entre as práticas, os seus modelos de racionalização e os quadros políticos globais" (MOSSE, 2005, p. 182) ${ }^{11}$.

Diferentemente dos projetos de desenvolvimento rural na Índia, analisados por Mosse (2005), a opção pelo cultivo de variedades híbridas e transgênicas dificilmente pode ser vista como um projeto de desenvolvimento, mas sim como um amplo empreendimento, alocado n'algum projeto de desenvolvimento. Dessa forma, para analisarmos como as variedades transgênicas são introduzidas e vendidas entre os agricultores de Canguçu, trazemos aqui o relato de um evento no qual foi discutida a produção de milho no município. É interessante pensarmos essas atividades não apenas como um evento de ordem agrícola e produtiva, mas sim enquanto momento simbólico que mobiliza agricultores, em especial, mas também a sociedade como um todo, com a finalidade de gerar simpatia e "encantamento" por meio dos discursos tecnológicos e de desenvolvimento.

O evento se denominava "Seminário sobre a produção e manejo do milho" e foi promovido pelo escritório local da Emater-RS ${ }^{12}$ e o Sindicato dos Trabalhadores Rurais/Fetag-RS (STR). Os principais objetivos do evento eram: Fornecer conhecimento técnico sobre a produção de milho e as melhores formas de secagem e armazenamento do grão; Divulgar e premiar os produtores "campeões" na produção individual de milho no município e fomentar uma "competição sadia" entre os agricultores participantes, e; Alavancar a campanha "Colha mais milho", promovida por aquelas duas instituições, que visava incrementar a área plantada e a produção de milho no município. Além dos agricultores, participaram do evento autoridades locais da secretaria

11 Ribeiro (2008) também aponta que projetos de desenvolvimento se concretizam por meio de uma complexidade de redes que conectam "fluxos não-lineares de trabalho, capital e informação" que integram níveis "locais, regionais, nacionais, internacionais e transnacionais" (RIBEIRO, 2008, p. 112) de atuação. Vale destacar que o conceito de rede usado por Ribeiro (2008) não é o mesmo de Mosse (2005), o qual se vale da abordagem de Bruno Latour. Outros escritos de Mosse apresentam e complementam igualmente estas opções analíticas, tais como em Mosse (2013) e Mosse e Lewis (2006).

12 Empresa de Assistência Técnica e Extensão Rural. Além da atuação no Rio Grande do Sul, a Emater está presente em distintas unidades da Federação. 
de desenvolvimento rural e agricultura. Técnicos agrícolas palestraram sobre os assuntos propostos, os representantes das instituições e de empresas do agronegócio, além das fornecedoras de sementes, também estiveram presentes.

As falas de abertura e introdutórias do evento foram proferidas pelos representantes das entidades promotoras. O representante do STR iniciou cumprimentando a presença de todos e principalmente dos representantes das empresas. Enfatizou que o sindicato tem uma "parceria e companheirismo com as empresas do milho de longa data", referindo-se às sementeiras, e que eventos como aquele serviam para fortalecer esses vínculos. Ao falar sobre a campanha "Colha mais milho", mostrando os resultados daquela que era a primeira safra da campanha, elencou alguns fatores que influenciaram na produtividade, citando as empresas e marcas de variedades de milho transgênico plantadas. Pontuou que produtores de variedades de milho crioulo e varietais não participaram da campanha, sem apresentar argumentos e justificativas para essa ausência. O objetivo da campanha em longo prazo, segundo o representante, é tornar Canguçu o maior produtor de milho em área plantada do Rio Grande do Sul, sendo que atualmente o município já possui este status na região sul do estado. Uma motivação nostálgica para essa campanha é resgatar o título de "capital do milho", alcunha que o município recebeu durante os anos oitenta. Além disso, uma das consequências da campanha é que o incremento da produção de milho estimularia o desenvolvimento do município e da região.

O segundo orador foi o representante local da Emater/Ascar. Iniciou sua fala reforçando o papel do agricultor para o desenvolvimento do município. Afirmou que o agricultor é na verdade um "aventureiro". Aventureiro, pois a atividade agrícola por si só já é repleta de riscos e, consequentemente, o agricultor tem uma vocação a arriscar-se, de querer inovar, produzir mais. Para exemplificar ele apontou que, devido a essas características, a família rural sempre escolhe a tecnologia e, naquele contexto, as escolhas eram pelas tecnologias dos milhos melhorados em laboratório. Segundo o representante, isso se deve ao fato de que essas novas tecnologias geram novas possibilidades produtivas e econômicas para os agricultores.

Ao conduzir sua preleção para o final, pontuou que o cultivo e a cadeia produtiva do milho estão intimamente relacionados à segurança alimentar. Não somente de quem o produz, mas da população em geral, pois do milho derivam ou alimentos ou forragens animais que, posteriormente, serão beneficiados em produtos alimentícios. Concluiu salientando que o milho é um cultivo da agricultura familiar, do pequeno agricultor, em oposição ao cultivo da soja que é 
a escolha das grandes propriedades. Após o momento das explanações técnicas, o evento foi conduzido para seu término com a premiação aos agricultores que, individualmente, produziram mais quantidade de milho. Entre os vários prêmios, destacamos a entrega de sacos de sementes de milho e insumos ofertados pelas empresas sementeiras.

A partir do relato acima podemos observar que o incentivo para o uso e plantio de variedades de milho transgênicas conta com fortes e importantes fomentadores do cenário agrícola, o órgão classista (sindicato dos trabalhadores rurais), o órgão estatal de extensão técnico-rural (Emater/Ascar), a iniciativa privada (empresas das sementes, e parte interessada na divulgação dessas variedades) e os próprios agricultores. Ao dizer que o STR tem uma "parceria e companheirismo com as empresas do milho de longa data"13, seu representante evidencia o comprometimento do órgão em vender ${ }^{14}$ não somente os produtos destas empresas como também suas ideias aos agricultores. A presença do representante e dos técnicos da Emater/Ascar ${ }^{15}$ também evidencia os interesses estatais com os das empresas do agronegócio. Entidades de extensão rural têm um papel histórico de longa data no difusionismo dos ideais, preceitos e práticas da modernização da agricultura entre a mais variada diversidade de agricultores. Quando as agências estatais optam por estes cultivos e tecnologias, e não outros, acabam convertendo uma ideia/projeto em realidade (neste caso os projetos de modernização da agricultura e de desenvolvimento). Cabe destacar que o consumo direto (na forma de grãos e forragem) ou indireto (alimentos) acabam reforçando a indústria agroalimentar de produtos transgênicos.

Eventos como este seminário, além de desvelar de forma mais cristalina e horizontal o empreendimento relacionado às sementes híbridas e transgênicas, prestam-se para legitimar o empreendimento em si mesmo. Como aponta Mosse (2005), independente de transformar realidades ou não, projetos de desenvolvimento considerados exitosos:

Sustentam modelos de políticas que oferecem uma interpretação significativa dos eventos. Eles são feitos com sucesso por processos

13 Informação fornecida pelo presidente do Sindicado dos Trabalhadores Rurais de Canguçu, em Canguçu, durante o Seminário de produção e manejo do milho, em 2016.

14 A venda aqui toma um sentido literal, pois o STR local possui um programa de venda de sementes de milho subsidiado no qual oferta apenas variedades híbridas e transgênicas, excluindo as variedades crioulas e varietais.

15 Destacamos que dentre o corpo técnico da Emater local, há técnicos que viabilizam outras formas de assistência e intervenção, que envolvem atividades relacionadas a outros modelos produtivos e de agricultura, entre estes os das sementes crioulas. Esta característica não homogênea das entidades voltadas à extensão também ocorre na área de pesquisa pública e, vale afirmar, em muitos estados da federação. 
sociais que dispersam a agência de projeto, forjam e mantêm redes de apoio e criam uma audiência pública para seu trabalho de transformação de social (MOSSE, 2005, p. 181, grifos nossos).

Ou seja, encontros como o "Seminário..." podem ser vistos como espaços similares a audiências públicas que têm por objetivos, primeiramente, legitimar as variedades transgênicas entre os próprios interessados - agricultores, estado, sementeiras - e para com a comunidade em geral. Além disso, servem como espaço para a divulgação e vendas (futuras) de novas variedades.

Mosse (2005) aponta ainda que há uma estreita relação entre representação e sucesso, sendo que a representação forte de um projeto alavanca seu sucesso. Assim, para garantir uma representação fortalecida muitos projetos de desenvolvimento estabelecem uma relação dupla entre o que realmente é realizado na prática e o que está nos modelos normativos do projeto. No limite, os gestores dos projetos são orientados a administrar as contradições e relações de poder internas inerentes aos projetos e investir na "publicização" de uma imagem homogênea, relegando um enfrentamento reflexivo dessas próprias contradições.

Esta relação dupla pode ser entendida por meio das estratégias que os promotores dos projetos e empreendimentos lançam mão para persuadir e convencer as populações locais da eficácia do que estão propondo. Nesse sentido, o "Seminário...", ao promover a competição e premiar os campeões de produtividade, fomenta a competição e o sucesso não apenas dos agricultores, mas implicitamente das variedades transgênicas e de todo o modelo produtivo. Assim, quanto mais expressiva e disseminada a interpretação do sucesso, melhor se estabelece tal iniciativa ou processo.

\section{ENTRE O SUCESSO E FRACASSO O DESENVOLVIMENTO AINDA PRODUZ DESEJOS}

Da reflexão que estabelecemos anteriormente, o leitor poderá imaginar que um etnógrafo como David Mosse está preocupado com os laços e as formas interpretativas locais que produzem sucesso do desenvolvimento e, assim, conduzam determinada sociedade ou região a melhores condições de vida e bem-estar. Não se trata disto. Se um programa ou projeto pode ter sucesso é porque existe um conjunto de instituições e pessoas que possibilitam sua coesão interpretativa. Sua pesquisa etnográfica mostrou que isto é momentâneo e dependerá dos elos destas ligações, dos contextos político-econômicos e outros fatores no conjunto sócio-técnico implicado. O corolário disto é que sucesso e fracasso não são definitivos ex ante para o autore, portanto, a linearidade progressiva 
dos projetos por meio dos quais pensam formuladores e mediadores dá lugar a algo propenso a muitas idas e vindas, altos e baixos. Isto exclui o ponto de vista do autor de uma perspectiva finalista. O que se destaca, de qualquer maneira, é a probabilidade de que fracassos em projetos de desenvolvimento sirvam não para condená-los, tal como a literatura em torno do pós-desenvolvimento costuma considerar; ao contrário, a frustração e o erro geram a reprodução do aparato e a novas tentativas "de desenvolver" os outros. Partindo da proposição de que fracasso e erro acabam por tornarem-se promotores de "mais" desenvolvimento, lançamos mão do estudo de James Ferguson (1990) sobre as falhas dos programas de desenvolvimento ${ }^{16}$ e como elas operam como um "retroalimentador" para novos projetos.

Ferguson está preocupado em evidenciar como o desenvolvimento e os projetos que são concebidos a partir dele vêm fracassando constantemente e mesmo assim permanecem vivos e sempre se reinventando. Para ele há uma "indústria do desenvolvimento" (FERGUSON, 1990, p. 8) que necessita constantemente lançar novos projetos e que cada lançamento gera repetidamente novos fracassos, configurando assim o fracasso/falha uma norma de todo o circuito. Ou seja, ainda que nos planejamentos e documentos preveja o êxito, os fracassos justificam e reafirmam a necessidade de novos projetos para reparar estes “efeitos colaterais" (FERGUSON, 1990, p. 252).

A ideia de fracasso de Ferguson (1990) difere da de Mosse (2005), pois para este último o fracasso seria resultado de uma comunidade fraca (sem capacidade de fornecer interpretação persuasiva sobre os benefícios do projeto) e que não daria sustentação para que o projeto ganhasse crédito entre os envolvidos e consequentemente seu sucesso. Particularmente, Mosse nos mostra que qualquer rede forte pode perder a força se perder adesão de membros, justamente a comunidade interpretativa que o sustenta. Já para Ferguson o fracasso é uma consequência constante dos projetos, independente da rede de relações que lhe sustenta. A questão de Ferguson, inspirada na obra de Michel Foucault, é o que o desenvolvimento faz (produz) - seja exitoso ou não - e não o que deixa de fazer.

$\mathrm{Na}$ sequência de seu trabalho o autor propõe que o desenvolvimento compõe uma entidade social autônoma, com instituições próprias, que ganha vida independentemente do Estado, mas que acaba favorecendo a expansão do poder estatal. No limite, o Estado vale-se dos projetos de desenvolvimento para "chegar" a locais onde não tem controle, através de escolas, postos de saúde,

${ }^{16}$ O estudo de Ferguson foi realizado no Reino do Lesoto, que é um pequeno país africano incrustado no território da África do Sul, que tem na agricultura e pecuária de caprinos suas principais atividades produtivas, além de contar o ingresso de dividendos oriundo do envio de dinheiro de parte de sua população que trabalha na África do Sul. 
estradas, postos de ajuda humanitária, segurança e extensão técnica. Para Ferguson, deste modo, o desenvolvimento se constitui uma "máquina antipolítica" que "despolitiza tudo o que toca" (FERGUSON, 1990, p. 255-56), tecnificando os discursos e as práticas justamente para evitar a politização dos problemas sociais. Ou seja, há uma padronização para a resolução dos problemas locais que devem ser administrados e resolvidos por meio dos saberes técnico-científicos, engenharias, agronomia, biotecnologia etc. Assuntos que poderiam passar pelo crivo político tal como a desigualdade, e discutida democraticamente - são tornados assuntos a serem resolvidos por metodologias e técnicas. Tal ideia se aproxima muito do escrito por Escobar (2007) que afirma que além da simplificação da vida, projetos e empreendimentos de desenvolvimento fazem diagnósticos sociais, escalonam a vida dos povos, criam quadros e matrizes explicativas sobre os problemas do subdesenvolvimento, isto é, por meio de técnicas e de saberes especializados.

Parece-nos que o "fracasso" no tocante às variedades transgênicas reside justamente nas ideias de que possibilita a expansão de políticas e práticas estatais, na simplificação da vida e na geração de pobreza. Variedades transgênicas vendem e produzem o imaginário que ao cultivá-las os agricultores terão mais facilidades, elevarão suas produtividades e consequentemente a renda. No entanto, a propaganda pouco fala dos elevados custos de produção, da necessidade de capital para a reprodução anual desse sistema, dos royalties e a capacidade de endividamento de cada agricultor para lograr a renda apregoada. Tal como comentou o sr. Zé Luís Porto quantas sacas por hectare a mais são necessárias somente para custear a produção? Para o endividamento e o subsequente empobrecimento de pequenos agricultores, poucas safras bastam. Mosse (2005), em sua análise de um projeto de desenvolvimento rural na Índia, aponta algo semelhante:

Enquanto a filosofia IBRFP [do projeto em questão] insistia na autossuficiência, o projeto abriu (ainda mais) a porta para insumos da agricultura, crédito para a produção e cultivo comerciais. Novos cultivos e novos estilos de vida exigiam mais gastos com fertilizantes, roupas, remédios, utensílios, verduras, óleo, para mostrar as longas listas por meio das quais os aldeões explicavam o aumento do custo de vida (MOSSE, 2005, p. 224).

Estes desdobramentos, por mais que não sejam os desejados pelas instituições que gerenciam e executam os projetos de desenvolvimento, acabam "retroalimentando" outras instituições "para o" desenvolvimento, que terão que reparar estes efeitos colaterais. Além disso, possibilitam que instituições e políticas estatais se estabeleçam naqueles ambientes, ou como medidas mitigatórias das ações fracassadas, ou como parte de determinado 
projeto político-estatal. Ferguson (1990), contudo, é mais contundente nesse sentido, pois afirma que a transformação e expansão da atividade agrícola, por exemplo, são apenas os objetivos primários dos projetos de desenvolvimento. Seu escopo final é a expansão e fortalecimento dos aparatos e poderes estatais de governo e da lógica capitalista.

No cenário agrícola brasileiro é recorrente que empresas e cooperativas incentivem seus agricultores sócios ou cooperados para que produzam determinada variedade de interesse, com a promessa de compra de toda a produção, levando as famílias a um grande investimento a fim de incremento da renda. Contudo, no momento de receber a produção negam-se adquirir, alegando não terem condições para tal, ou que o produto é de baixa qualidade, ou ainda aceitam receber pagando um valor que muitas vezes não cobre nem os custos de produção.

Situações como esta acabam possibilitando que os regimes de desenvolvimento se complementem dentro do capitalismo global, pois gerará outros projetos para "reabilitar" estes agricultores, sejam eles projetos de financiamento, seja modernização da propriedade a fim de "garantir" a qualidade dos cultivos vindouros. Desde um olhar através do empreendimento das sementes transgênicas, os mecanismos e projetos passam por lançar variedades com novas tecnologias - mais caras e com a necessidade de um pacote de insumos mais específico - que prometem novamente mais qualidade e produtividade.

Outro efeito, apontado por Ferguson, decorrente das falhas dos projetos de desenvolvimento, é uma patente simplificação da vida das pessoas, por meio da despolitização e burocratização dos cotidianos (FERGUSON, 1990, p. 256). Levando em consideração que os organismos transgênicos façam parte desses aparatos de desenvolvimento, é possível, a partir deles, pensarmos em consequências (ou falhas nos termos de Ferguson) simplificadoras.

Shiva (2003, p. 91) argumenta que dentro do paradigma do agronegócio "a diversidade se opõe à produtividade, criando um imperativo de uniformidade e monocultura", para na sequencia afirmar que "a crise da biodiversidade está relacionad[a] ao fato de que as biotecnologias são, em essência, tecnologias da uniformidade em plantas e animais" (SHIVA, 2003, p. 138). Ou seja, a promoção ao plantio e produção de grãos oriundos de transgenia acarreta em uma forma de simplificação da vida, por meio tanto na homogeneização da agricultura como das formas de agriculturas (que se relacionam aos conhecimentos agrícolas locais/ tradicionais). Temos ainda como consequência a crescente perda de variedades agrícolas, que foram melhoradas ao longo da prática agrícola, em um curto espaço de tempo a expensas do binômio (bio)tecnologia/produtividade. Analisando o 
conjunto total de projetos de desenvolvimento, Escobar (2007, p. 248) destaca que "em contraste com a extrema heterogeneidade da realidade camponesa, iniciativas [de desenvolvimento rural] tendem a criar estratos relativamente homogêneos mediante a imposição de certas práticas".

Por fim, cabe mencionar que os projetos de desenvolvimento necessitam de um eficiente aparato que produza novas projeções, independente dos resultados obtidos nas comunidades. Para Mosse (2005):

Se os projetos bem-sucedidos são aqueles que se assemelham aos modelos de políticas dos doadores, então as agências de desenvolvimento são levadas a melhorar a gestão de suas representações, ao dirigir seus esforços práticos para preservar a identidade, nenhum dos quais feitos para melhorar as oportunidades de aprendizagem ou eficácia na redução da pobreza (MOSSE, 2005, p. 203).

Isto é, para o autor a gestão dos projetos é conduzida para manter a identidade dos mesmos em consonância com as agências financiadoras, pois politicamente é muito mais relevante do que os resultados em si. Dessa forma, novos financiamentos poderão ser obtidos e, assim, mais ações e novas intervenções poderão ser planejadas. Ferguson (1990), por sua vez, aponta que na indústria do desenvolvimento o que importa é uma fórmula de aplicabilidade dos projetos, independente das especificidades e dos resultados que gerarão. Pois, de qualquer modo, no momento de execução, estratégias bem definidas de planejamento interagirão com estruturas não previstas e eventos imprevisíveis, acarretando nos seus fracassos.

\section{CONSIDERAÇÕES FINAIS}

Neste artigo, buscamos mostrar que a adoção dos transgênicos tem efeitos diversos que, independente de representarem sucesso ou fracasso do desenvolvimento, geram desejos, subjetividades e relações que (re)produzem desigualdades. Com os apelos de produtividade e facilidade, os transgênicos ganham produtores. É de se notar, no entanto, que quando se tornam significativamente disseminadas as variedades transgênicas, crescem também as iniciativas em torno de sementes crioulas, envolvendo atores variados, tais como: agricultores, mediadores de diversas ONG, técnicos e pesquisadores de empresas públicas de pesquisa e extensão rural e agrícola. Bancos de sementes comunitários se tornam recentemente mais comuns no Brasil e se pode afirmar que são obras protagonizadas por agricultoras e agricultores familiares. 
Pode-se observar que apesar das promessas de facilidade e produtividade que se articulam com um tipo de desenvolvimento almejado por empresas e entidades, as iniciativas esbarram em problemas, tais como: os elevados custos de produção, os royalties a serem pagos e o endividamento de muitos produtores. Para agricultores que optaram pelas sementes crioulas, há benefícios justamente nos menores custos, na circulação das sementes de modo livre e nos saberes locais associados.

Ao longo do trabalho, entrevistas e eventos foram examinados para elucidar a delicada relação entre os agricultores familiares e os transgênicos. Parte desta narrativa se esforçou em salientar como os agricultores entrevistados, bem como outros atores, falam e se posicionam em relação ao tema. Este conjunto de narrativas nos conduziu a estudos anteriores relativos à relação entre agricultura e desenvolvimento, especialmente os produzidos por Arturo Escobar, David Mosse e James Ferguson. Particularmente, a importância de destacar as monografias de Mosse (2005) e Ferguson (1990) reside em mostrar como estas etnografias forneceram elementos para a análise em questão, uma vez que falhas momentâneas, produção discursiva do sucesso ou ainda a sensação de fracasso geral permeiam as iniciativas envolvendo transgênicos.

Para a indústria de transgênicos e de biotecnologia agrícola podemos observar práticas de produção de sucesso, com investimento em coerência e identidade dos projetos ou em aplicabilidade de modelos de desenvolvimento em qualquer lugar e menos preocupação com aprendizagem real dos atores ou diminuição da pobreza. Para tal consecução, o caso dos transgênicos demonstra que os objetivos finais são produzir produtos, desde os artefatos considerados sementes até todos os insumos do pacote tecnológico necessário para plantar e produzir. Isso se faz independentemente das especificidades culturais de quem as plantará ou dos danos ambientais à biodiversidade e à saúde humana, que geram tanto a sua manipulação como os produtos finais dentro da cadeia agroalimentar.

\section{REFERÊNCIAS}

ABRAMOVAY, R. Paradigmas do capitalismo agrário em questão. 2. ed. São Paulo: Anpocs: Unicamp: Hucitec, 1998.

BRUSH, S. Protecting traditional agricultural knowledge. Journal of Law and Policy, [S. l.], n. 17, p. 59-109, 2005. 
CARNEIRO, M. Práticas, discursos e arenas: notas sobre a socioantropologia do desenvolvimento. Sociologia \& Antropologia, Rio de Janeiro, v. 2, n. 4, p. 129-158, 2012.

CESARINO, L. Anthropology of development and challenge of South-South cooperation.Vibrant, [S. l.], v. 9, n.1, p. 509-537, 2012.

DeVRIES, P. Don't compromise your desire for development! A Lacanian/ Deleuzian rethinking of the anti-politics machine. Third World Quarterly, [ $S$. l.], v. 28, n. 1, p. 25-43, 2007.

ESCOBAR, A. Comunidades negras de Colombia: en defensa de biodiversidad, territorio y cultura. Biodiversidad, [S. l.], n. 22, p. 15-20, 1999.

ESCOBAR, A. El "postdesarrollo" como concepto y práctica social. In: MATO, D. (org.). Políticas de economía, ambiente y sociedad en tiempos de globalización. Caracas: Universidad Central de Venezuela, 2005. p. 17-31.

ESCOBAR, A. La invencion del tercer mundo. Caracas: El perro y la rana, 2007.

ESTEVA, G. Desarrollo. In: SACHS, W. (org.). Diccionário del desarrollo: una guía del conocimiento como poder. Lima: Proyecto Andino de Tecnologías Campesinas, 1996. p. 52-78.

FERGUSON, J. The anti-politics machine: "development", depoliticization, and bureaucratic power in Lesotho. Cambridge; New York, Cambridge University Press, 1990.

GOLDMAN, M. Imperial nature. The World Bank and struggles for social justice in the age of globalization. New Haven; London: Yale University Press, 2005.

INGOLD, T. Time, memory and property. In: WIDLOK, T.; TADESSE, W. G. (ed.). Property and equality: ritualisation, sharing, and egalitarism. New York: Berghan Books, 2005. p. 165-174.

KAPOOR, I. The postcolonial politics of development. London: Routledge, 2008.

LI, T. Locating indigenous environmental knowledge in Indonesia. In: ELLEN, R.; PARKES, P.; BICKER, A. (ed.). Indigenous environmental knowledge and its transformation: critical anthropological perspectives. Amsterdam: Harwood Academic, 2000. p. 121-149. 
LI, T. The will to improve: governmentality, development and practice of politics. Durham: Duke University Press, 2007.

MELGAREJO, L. Entre a miopia destrutiva e resiliência construtiva: dez anos de transgenia e agroecologia no Brasil. Agroecologia e Desenv. Rural Sustentável, Porto Alegre, v. 6, n. 1/2, p. 67-70, 2013.

MOSSE, D. Cultivating development: an ethnography of aid policy and practice. Londres: Pluto, 2005.

MOSSE, D. The anthropology of international development. Annual Review of Anthropology, [S. l.], v. 42, p. 227-246, 2013.

MOSSE, D.; LEWIS, D. Theoretical approaches to brokerage and translation in development. In: LEWIS, D.; MOSSE, D. (ed.). Development brokers and translators: the ethnography of aid and agencies. Bloomfield, Kumarian Press, 2006. p. 10-26.

NAZAREA, V. Local knowledge and memory in biodiversity conservation. Annual Review of Anthropology, [S. l.], v. 35, p. 317-335, 2006.

OLIVEIRA, R. C. de. O trabalho do antropólogo. São Paulo: Ed. da UNESP, 2006.

PERROT, D. Quem impede o desenvolvimento "circular"? (Desenvolvimento e povos autóctones: paradoxos e alternativas). Cadernos de Campo, São Paulo, n. 17 , p. 219-232, 2008.

QUINTERO, P. Antropologia del desarrollo: perspectivas latino-americanas. Buenos Aires: Kula, 2015.

RIBEIRO, G. L. Poder, redes e ideologia no campo do desenvolvimento. Novos Estudos CEBRAP, São Paulo, v. 80, p. 109-125, mar. 2008.

RIST, G. El desarrollo: historia de una creencia occidental. Madrid: Catarata, 2002.

SACHS, I. Desenvolvimento e cultura. Desenvolvimento da cultura. Cultura do desenvolvimento. Organizações \& Sociedade, Salvador, v. 12, p. 151-165, 2005.

SHEPHERD, C. Agricultural hybridity and the "pathology" of traditional ways: the translation of desire and need in postcolonial development. Journal of Latin American Anthropology, [S. l.], v. 9, n. 2, p. 235-266, 2004.

SHIVA, V. Monoculturas da mente: perspectivas da biodiversidade e da biotecnologia. São Paulo: Gaia, 2003. 
UNAIC. União das Associações Comunitárias do Interior de Canguçu.

UNAIC, [S. l.], [2016]. Disponível em: http://unaic.blogspot.com.br/. Acesso em: 14 set. 2016.

WOORTMANN, E. F. Herdeiros, parentes e compadres: colonos do Sul e sitiantes do Nordeste. São Paulo: Hucitec; Brasília: Edunb, 1995.

\section{ENTREVISTAS}

FERREIRA, C. Entrevista realizada em 20 de fevereiro de 2016, Canguçu, Rio Grande do Sul/BR.

PORTO, J. L. (Zé Luís). Entrevista realizada em 04 de junho de 2016, Canguçu, Rio Grande do Sul/BR. 
